\title{
Second language identity
}

\author{
B. Zhalehgooyan
}

\section{Focus}

The focus of this study is to review some existing explanations for the terms identity and second language acquisition (SLA) in the literature and then addressing the question of how identity could affect second language teaching.

\section{Identity}

Zimmerman (as cited in Antaki \& Widdicombe, 1998, p.90) identified three different kinds of identity in his talk:

Situated identity: explicitly used in a particular context of communication such as doctor versus patient or teacher versus student identity. When the speaker is situated in a formal context he might change his accent in such a way that he could be judged as an educated person. Thus, this kind of behaviour is conscious.

Discourse identity: participants position themselves to specific discourse roles in the moment by moment of the interaction such as indicator, listener, questioner and challenger.

Transportable identity: which is either explicit or implicit and can be used during the interaction for the particular reason. For example, during a lecture or a lesson a teacher might refer to the fact that she is also a mother of two or an avid science fiction fan.

McNamara, Hansen and Liu (as cited in Norton, 2013) defined the term identity as the attempt people make to understand their relationship to the world, how that relationship is built across time and space, and how people see their possibilities for the future. Furthermore, Norton (1997) in his article agreed with West (1992) on that identity relates to tendency for recognition, the willingness to affiliation, and the desire for security and safety.

Stockton (2015) also stated in his study that the word 'identity' can be explained by the following terms: cultural, linguistic, ethnic, social, racial, gender, academic or literate, national, and class. However, if it was used without those qualifications it could be called 'unspecified'.

Norton (1997) again in the case of target language demonstrates identity as a motivation either instrumental or integrative. Identity in the role of instrumental motivation illustrates the language learner's willingness towards learning a second language for practical purposes, such as finding a job. However, identity as integrative motivation depicts their needs to learn a language in order to integrate successfully with the target language community and escape from being lonely. He also introduces the term investment to signal the socially and historically constructed relationship of learners to the target language and their desire to learn and practice it, but it is important to know the difference between the two terms; while motivation can be seen as a primarily psychological construct, investment is a sociological construct. Thus, in this way, he makes a meaningful connection between a learner's desire and commitment to learn a language and their changing identities.

According to Giles and Coupland (as cited in Jenkins, 2000) there are two different views regarding identity: first, language learners either accommodate their speech to that of the interlocutor in order to both be liked and understood; second, language learners proclaim themselves members of 
the interlocutors' communities. These views are also called nativeness principles, in which second language learners gain access to material resources, such as wealth, and symbolic ones, such as friendship, through convergence. The second view is called "Divergence phenomenon" in which the language learners try to distance their speech from that of the interlocutor in order to keep their own ingroup identity intact and stay loyal to their speech communities.

\section{SLA (Second Language Acquisition)}

According to Gass and Selinker's (2009) definition, "SLA is the study of how non-primary languages are learned. It is the acquisition of a language beyond the native language" (p. 1). An additional language is often called an L2, while an L1 represents a first language or a speaker's mother tongue. SLA researchers often try to address all the questions about how a learner makes a new language system in the L2, how well the new system is acquired, what influences L1 and L2 systems have on one another, whether all second language learners have the same patterns of acquisition, and much more. In fact, research about identity and second language acquisition began in the early 1970s, raised sharply in the 1990s, then continued to grow steadily, with a peak in 2008.

\section{Identity and SLA research findings}

Norton (2001) created the term 'imagined community' and used it in SLA theory. He explained its relationship in this way: when students learn a language, they will think about their future, learners imagine who they might be and who their communities might be. Such imagined communities may even have a strong reality. Thus, this kind of view can have a great impact on their investment in learning a language. Students only invest when they see an opportunity for personal profit. Furthermore, Norton argued that if language teachers do not have a sufficient knowledge about learners' imagined communities and imagined identities they won't be able to create learning activities in which learners can invest.

Regarding imagined communities, Norton (2001) discusses two women, Katarina and Felicia, whose investment reduced only because of not participating in imagined communities. Katarina, who had been a teacher for 17 years in her home country, Poland, was offended when her English was not good enough to participate in a career-oriented computer class. She considered herself as part of a community of professionals, but when she couldn't gain that identity her investment in language learning was suppressed.

On the other hand, Felicia, a Peruvian immigrant, found her teacher humiliating her home culture so she never went back to class. Although the two women's conditions were different, they both experienced situations in which their imagined communities were not accepted, and as a result their investment suffered.

Stockton (2015) reported the story of how learning English for the female EFL learners in Japan acted as a confidence boosting experience. As one of the learners said: "When speaking Japanese, it takes a lot of courage to express my convictions or insist upon my beliefs, but in English I can do so with a sense of being equal to the person I am talking to." (p. 27). Therefore, it can be inferred from this statement that the more successfully one can acquire a language the more confident and motivated one will be.

Any ESL classroom can be seen as a unique, complex, and dynamic social environment in which an individual brings their own unique identity to the class and shares it with other learners. Thus, through this classroom reflection and interaction, new cultural traditions, histories, and solidarities will be shaped which can increase their chances of having a better future. Here, the task of ESL teachers is 
to identify that classroom relationships and interactions then, both consciously and unconsciously decide what kind of teaching activity is suitable for the new language learners. One key element in identity focused SLA is the idea that individual language learners must be considered according to the language learning context and their needs to communicate with other peers in the target language.

Norton (2006) suggested that "there are five common beliefs about identity, underlying most identity-focused SLA research" (p. 3):

1. Identity is dynamic and constantly changing across time and place,

2. Identity is "complex, contradictory and multifaceted",

3. Language is both a product of and a tool for identity construction,

4. Identity can only be understood in the context of relationships and power,

5. Much identity-focused SLA research makes connections to classroom practice. (p. 3)

Norton and Toohey (2011) illustrate the case of Martina, an eastern European immigrant to Canada. Although, she was a highly educated person in her home country, she was only able to find a job in a restaurant and struggled with being called a 'broom'. Instead, she shifted to having another social identity as a 'mother'. This position enabled Martina to have a greater social access to target language (TL) relationships and communities, which is a major factor in second language learning. Furthermore, Norton and Toohey (2011) explained why women resisted speaking in certain situations. They found out that learners are characterized both by what they are and what they are not, if learners do not own an 'image' of themselves in a target community, they won't invest in learning the target language. Therefore, it is necessary for language teachers to help the learners see themselves as a member of the target society.

Hence, language learning is not only acquiring a linguistic code but is also learning how to accept a role or take a position in a vast social context. According to Ogulnick (2000), language learning is "a process of fitting into one's place in society, or rather, one's imposed place" (p. 170). So, part of language learning must be devoted to the acquisition of sociolinguistic competence. It can be defined as an ability to properly modify language according to communicative purposes, position of participants, location, discourse and other contextual factors.

In fact, people use language to "negotiate" their identities. Watkins-Goffman (2001) states that "every time we speak we are negotiating and renegotiating our identities" (p163). Language in this view, among the other options available to a speaker such as L1 or L2, dialect, register, style, intonation, or silence, becomes a tool for negotiating one's identity.

Bourdieu (1977) also believes the value which is assigned to speech cannot be realized without the person who speaks, and the person who speaks cannot be understood apart from his relationship to the social community. The ability to live and express an identity in second language relies on how much we attain the sociolinguistic competence. Having this ability motivates us to know the language and the target culture more, and facilitates the acquisition process.

Overall, from the past findings can be inferred that the best teaching method in an ESL classroom would be having a more student-centered class. Student-centered learning puts students' interests and needs first, acknowledging the student voice as central to the learning experience. In a student-centered class, students choose what they will learn, how they will learn, and how they will assess their own learning. Therefore, in this way, they will build their own sense of self and obtain more power to speak about their beliefs and represent their identity. They can contribute their ideas, feelings, and thoughts. Moreover, students can engage in critical thinking around identity issues and do not need to be limited to more surface-level language features like practicing some fixed and boring grammatical rules and repeating drills. In the end, the outcome of such a class would be having a number of more motivated students who are willing to invest in integrating into the target culture and language. 
Steele and Vargas (2013) found that "in higher identity-safe classrooms, students had higher scores on standardized tests, wanted challenging work, felt a greater sense of belonging, and felt more positive about school compared to students from less identity-safe classrooms" (p. 7)

Having a student-centered class in which their diverse identities are safe could be considered as a good method to teach English. Below are some ideas about how to create trust, autonomy, belonging, and competence in a classroom:

\section{Promoting Diversity as a Resource}

This idea uses student's diversity as a tool to create an exciting curriculum, it also promotes a less stressful and friendly environment in classrooms. As an example, every session, the teacher can introduce parts of each student's culture including different music, art, games, stories and movies, which inform other students and helps to build students' diverse identities. Through follow up activities, students can learn new words and enhance their speaking skills by talking about cultural events and ceremonies in different countries.

\section{Classroom Relationships}

One of the crucial elements for building students' identity in classrooms is a positive relationship between students. If students treat one another kindly, fairly and respect each other's diverse identities properly, a trust will be built among them. The availability, warmth, caring, and attentiveness of the teacher can accelerate student's trust and relationship. It has been suggested that teachers combine humour and tendency with meaningful academic content, while checking nobody is making fun of their peers and everyone is learning from each other's mistakes. Genuine warmth and friendliness go a long way towards creating a sense of belonging.

\section{Caring Classroom Environments}

This idea tries to build a classroom in which students emotionally and physically feel secure and also pays attention to students' social behaviour in the classroom. The emotional atmosphere of a classroom shows how comfortable and secure students feel. Attention to their prosocial development along with academic growth will support development in both areas. In order to have such a classroom, students need to practice some self-management skills, such as problem-solving and flexibility, because the teacher raises clear expectations and students should be able to manage themselves in a way that they don't get confused. Some suggestions could be:

- Put every student's work on the wall, even if it's not perfect;

- Present posters which include other people who look like your students;

- Introduce exercises which incorporate social skills into academic moments;

- See the classroom from different students' eyes. A teacher can do this by sitting in their seats to imagine how they feel in class.

\section{References}

Antaki, Ch., \& Widdicombe, S. (1998). Identities in talk. London: SAGE Publication.

Bourdieu, P. (1977). The economics of linguistic exchanges. Social Science Information, 16(6), 645668.

Gass, S., \& Selinker, L. (2009). Second language acquisition: An introductory course. New York: Routledge. 
Jenkins, J. (2000). The Phonology of English as an International Language. Oxford: Oxford University Press.

Norton, B. (1997). Language, identity, and the ownership of English. TESOL Quarterly, 31(3), 409429.

Norton, B. (2001). Non-participation, imagined communities, and the language classroom. In M. Breen (eds.) Learner contributions to language learning: New directions in research. Harlow, England: Pearson Education.

Norton, B. (2006). Identity as a sociocultural construct in second language education. In K. Cadman \& K. O'Regan (eds.), Tales out of school. Cambridge: Cambridge University Press.

Norton, B., \& Toohey, K. (2011). Identity, language learning, and social change. Language Teaching, 44(4), 412-446.

Norton, B. (2013). Identity and language learning. Great Britain: Short Run Press.

Ogulnick, K., (2000). Language crossings: Negotiating the self in a multi-cultural world. New York: Teachers College Press.

Steele, D.M, \& Cohn-Vargas, B. (2013). Identity Safe Classrooms Places to Belong and Learn. London: SAGE Publications.

Stockton, H.L. (2015). Identity-Focused Second Language Acquisition: A Systematic Review of Classroom Applications (Unpublished master thesis). Hamline University, Saint Paul, Minnesota. 